\title{
E-teaching as companion to e-learning; supporting digital pedagogies and practice in higher education
}

\author{
Sue Watling \\ University of Hull
}

\begin{abstract}
The literature of education technology suggests that greater attention has been paid to the student experience of e-learning than the development of academics as e-teachers.

Technology has been widely promoted as an 'enhancer' of student learning and there is an expectation that academics will make use of Virtual Learning Environments (VLEs). Indeed, the adoption of digital tools is an essential component of current interest in flipped and flexible approaches to higher education. However, the majority of VLE usage may more nearly resemble a digital document dump than the interactive and collaborative pedagogies predicted by the early promises of e-learning transformation (NCIHE, 1997). This paper seeks to shed light on the hitherto under-researched area of the relationships academics have with their VLEs, in particular with regard to reluctance or resistance to move from faceto-face to online practice. Whilst the sector has invested into inquiry into the aspirations and motivations of the digital student (Jisc, 2009), the day-to-day digital interactions of staff who teach and support learning and, in particular, those without technology expertise or natural digital inclinations, have gone largely unrecorded. This paper offers some preliminary findings of a three-year action research project investigating attitudes towards virtual learning though a teacher-education lens rather than a traditional technology-training one. Findings have been converted into advice for academics looking to make the shift from faceto-face to e-teaching and blended practices. This guidance for staff may be usefully positioned alongside what is already known about the student experience of e-learning.
\end{abstract}

\section{Introduction}

In contrast to the transformative promise of Technology Enhanced Learning (TEL), there were early indications that all was not well with both the adoption rate of new technologies and the rationale for moving to virtual design and delivery, whilst critical reviews have been explicit about the failure of VLEs (Liseweski, 2004; Bell and Bell, 2005; Conole, 2004; Clegg et al, 2003; Freisen, 2008; Saljo, 2009; Selwyn, 2013). Research into the value of technology has been accused of lacking rigour (Bennett and Oliver, 2011; Gunn and Steele, 2012) so that it becomes '...extremely difficult to trace the impact of educational research to anything that really matters' (Reeves et al, 2012:57). More recently, OER, MOOC, social media and mobile devices have revived early promises of transformation (Anderson, 2007; JISC, 2009; Conole, 2010), but enthusiasm contrasts with reports of low appetite for change (Heirdsfield et al, 2011; Sheward and Hamilton, 2012; Watling, 2009) and numerous reports cite deficits of time, support and appropriate resources to support academics to make the digital shift (Beetham et al, 2009; Walker et al, 2012; UCISA, 2012, 2014). Negative views like these have contributed to the gloomy conclusion put forward by Feenburg: '...the promise of virtual learning in the 1990s has come to nothing and elearning within the university has failed.' (Feenburg, 2011:2)

In the increasingly digital environment of higher education, individual reluctance to engage is often rendered invisible. Whilst like attracts like and technology enthusiasts work well 
together, those who might label themselves as 'digitally-shy' risk exclusion: less likely to read the TEL literature, attend TEL conferences or apply for TEL funding, the digitally shy or resistant are also less likely to get involved with institutional technology events or sign up for technology-training opportunities. However, the need for academics to come out from their analogue shadows has been recently highlighted. Lack of staff engagement was identified as a barrier to technology adoption (UCISA, 2010, 2012, 2014) whilst increasing digital engagement is explicit in the HEA's Flexible Pedagogies reports (Gordon, 2014). Further raised awareness of the experiences of academic staff, for example Ecclesfield et al (2014), has fed into the work Jisc has carried out around addressing the digital capabilities of staff who teach and support learning. This builds on earlier work by Jisc (Beetham et al, 2009) which underpins the recent development of a digital capabilities framework (Jisc, 2013, 2015) and partnership work with students (Healey et al, 2014; Killen and Chatterton, 2015). Raising awareness of the experiences of academic staff with technology has provided a useful first step, which is ideally followed by the identification of authentic ways to ensure that future digital engagement is encouraged, maintained and rewarded.

\section{Methodology}

Traditionally, VLE support has been located within the realm of technology training, whilst effective pedagogy has sat within teacher-education programmes. This paper addresses an attempt to bring the practical and pedagogical together through an accredited teacher education course, Teaching and Learning in a Digital Age (TELEDA), which was delivered and assessed entirely online. Based on the principles of experiential learning, staff were enrolled as students on the institutional VLE (Blackboard), where they engaged with digital tools and were asked to reflect critically on both transferring the experience to their own teaching and the effectiveness of the course as a means of digital CPD and teacher education. The aim of TELEDA was to enhance the e-learning experience of students by prioritising time and space for accredited e-teaching development. ${ }^{1}$

Developing TELEDA through an action research methodology reinforced the participatory nature of the course and maximised the unique position of participants as both learners and teachers. The TELEDA pedagogy aimed to expand knowledge production rather than reiterating traditional transmission and consumption models. There were no lectures on TELEDA. The learning was interactive and collaborative, grouped around individual subject blocks which covered Online Design, Introducing OER, Social Media and Digital Resources. Content was provided through text, images, audio and video, but focused primarily on discovery and discussion. Participants were asked to search for relevant content, which might be papers or multimedia resources, which was collected and shared using social bookmarking tools. Twitter was used for synchronous and asynchronous tweet chats, providing opportunities for engagement in supportive collegial groups. Course design utilised the Five Step Model of e-moderating (Salmon, 2000) with collaborative activities built around the Conversational Framework (Laurillard, 2001). Constructivist scaffolding from the tutor supported the early stages of participant engagement with virtual ways of working, with this

\footnotetext{
1 The TELEDA course emerged from a twelve-month, HEA-funded project, Embedding OER Practice (Watling, 2011), which bought together academics with a primary interest in educational development rather than technology, but who developed digital capabilities as the project progressed. This became the catalyst for the development of TELEDA, which aimed to support academic confidence with digital pedagogies and practice.
} 
gradually being withdrawn as levels of digital confidence increased. Throughout the course, participants were expected to interact with content and colleagues, while all the time traversing the iterative rounds of the experiential learning cycle.

\section{Data Analysis}

The key outcomes from TELEDA have been synthesised into three areas of advice for aspiring e-teachers and staff in departments supporting CPD and teacher education. These three areas include suggestions for mitigating any potentially negative consequences from TEL engagement and turning them into positive outcomes.

\section{Avoid the 'myths of digital confidence'}

"I have made assumptions previously about the skills of students I am working. I presumed they would find learning in an online environment 'easy' as this was something that they had chosen. I was wrong." (Watling, 2015)

Making over-ambitious assumptions about digital ways of working risks lack of engagement in TEL opportunities, low enthusiasm for digital activities and poor retention rates. Myths of digital confidence are prevalent amongst those who support and mandate technology and fail to empathise with digital fear or diversity. While some academics might be openly frank about their perceived lack of digital aptitude, others may appear digitally confident but lack experience with VLEs for academic purposes. Digital working styles are as unique as individual handwriting or fingerprints. Everyone operates online in different ways, which makes it problematic to apply a 'one-size-fits-all' digital competencies' checklist or framework.

\section{Advice for avoiding the myths of digital competence includes managing learner expectations and building in time for digital practice}

Students take cues from tutors and, if the tutor is negative about the VLE or provides poorlystructured online resources, then they will be less likely to engage (Masterman, 2010). Addressing e-teaching is an opportunity to improve the e-learning experience. Time to practise communicating online (for example, an introductory forum which includes tasks like attaching a file or uploading a photograph) offers safe space to experiment. A 'hopes and fears' activity, which encourages sharing previous digital experiences, might reveal unexpected gaps in knowledge and indicate where appropriate support and guidance is needed. Discussion forums and activities using wikis, blogs or journals do need to be nurtured.

"I realise now how naïve I was in the past to simply open the discussion board with a question and expect the students to participate. As a tutor I have to make it possible for my students to participate through the design of my tasks." (Watling, 2015)

Some participants may feel nervous about going first or making a mistake, whilst confident others can dominate any fledgling conversations. Sensitive approaches are required. Since the absence of face-to-face clues can cause online messages to be misinterpreted, 'netiquette' advice, either pre-formed or developed by the group, is useful. Guidance might include avoiding capital letters (which can be perceived as shouting) and to use emoticons to convey intended emotions like humour or fear. This might all seem unnecessary in these 
days of email and social media, but professional communication is a valuable attribute and the ability to manage this appropriately in a range of digital media should not be assumed (Salmon 2011, 2013).

\section{Coping with identity blur}

"I now realise the transition from being an effective classroom practitioner to an effective online practitioner is complex and challenging." (Watling, 2015)

The term 'e-lecturer' is rarely seen. The literature includes labels like facilitator, instructor, moderator and trainer whilst Goodyear et al (2004) listed eight different roles an effective eteacher needs to perform. The emotional impact of the shift from 'sage on the stage' to 'guide on the side' should not be underestimated. Reliance on digital media contrasts with the traditional social and personal nature of education, whilst teaching online involves coming to terms with varying degrees of invisibility. Establishing an identity and rapport has to be worked at and TELEDA invited students to post photographs and short introductory video. Using blogs or wikis for asking questions and setting specific times for responses can establish VLE visit routines. Though the lack of instant face-to-face cues and feedback often appears challenging, this is always balanced by the beneficial capacity of VLEs to cross traditional barriers of time and distance, to encourage student-centred, independent learning and to ensure that everyone has an equal opportunity to participate.

\section{Advice for coping with identity blur includes ensuring interactive and experiential approaches within online learning designs}

"It seems obvious now that the lack of student engagement with my online resources was due to inappropriate design. I placed too much emphasis on text based, selfdirected learning and didn't recognise the important role of interaction between students and probably most importantly, investing time in building solid foundations and helping students develop skills for online learning." (Watling, 2015)

Since digital resources have to work hard to sustain audience interest, the adoption of activity-based content ( $A B C$ ) is more likely to prevent enthusiasm lapse than passive transmission methodology. Activities should include tasks, problems and choices with opportunities for students work in pairs, threes or larger groups. Allocating roles (such as task scribe, collector of content or reporter for sharing the group experience to peers) can maintain momentum. Traditional face-to-face content such as that transmitted in lectures rarely translates well to online environments. A fifty-minute recording, complete with coughs, sneezes and a blank wall when the lecturer has moved away from the camera, can be made more effective if edited into smaller blocks, with summary information or formative assessment questions slotted between sections. A narration over a set of presentation slides has all the advantages of an online resource; it can be revisited, stopped, started and accessed at a time and place of the student's choice. However, the potential for a more meaningful approach to digital learning will always be enhanced if multiple media are deployed to present content via more stimulating, interactive peer activities.

The literature on digital education offers different approaches and ideas (Salmon, 2011, 2013; Laurillard, 2001; Garrison, 2014), but the most valuable CPD activity is an experiential or immersion approach, which can be achieved through taking part in a MOOC. 
"The experience of being isolated and lacking human connection also supported my feeling about the importance of the social in the learning experience. There are lots of ways to connect I didn't know about." (Watling, 2015)

Massive Open Online Courses (MOOCs) offer free opportunities to experience the emotions involved in learning online. These can include fear, frustration and time constraints, the effect of which on attainment should not be underestimated. MOOCs show how other institutions are exploring virtual learning. They give access to ideas for both the design and delivery of content as well collaborative activities. Some large courses have fixed start and end dates, involve synchronous or asynchronous discussions and peer review, but can still be joined at any time or dropped in and out of. MOOCs can also comprise smaller chunks of learning which are each more like an Open Educational Resource (OER) and can be undertaken individually. Courses offered by Futurelearn², the partnership between the OU and a consortium of UK universities, are worth exploring, whilst the Khan Academy ${ }^{3}$, Coursera ${ }^{4}$ and Udacity ${ }^{5}$ have a range of short and long MOOCs. The value of any MOOC experience is the view of VLE from the e-learner perspective. This offers aspiring e-teachers insight which can be used to enhance the effectiveness of the design and delivery of their own online resources.

\section{Preparing for a 'pedagogy of uncertainty'}

"Being an online learner is confusing and disorientating. There is no tutor to check what you are doing 'is right'.... as a tutor in the classroom you can be on hand to make connections for students or clarify activity instructions, this is less easy online, you have to almost pre-empt questions." (Watling, 2015)

VLEs offer a blend of benefits and barriers but all usage involves a sense of uncertainty deriving from lack of face-to-face contact. It can be difficult to see if e-learners have arrived online and accessed resources or to know if they will engage in activities. Though this is true of all educational opportunities, it can be harder to assess when students cannot be immediately seen or heard. VLE monitoring features are useful indicators of presence, whether actively engaged with resources or not, but less helpful with regard to the quality of individual engagement. However, uncertainty must not be perceived as wholly negative. It can also involve surprise and delight, such as when end-of-block or end-of-course feedback shows students had engaging and productive experiences which they valued and appreciated. The advantages of VLEs to cross barriers of time and distance, and ensure equal participation in activities, will always offer a positive balance to what can feel like negative trials and tribulations of e-teaching.

"As a novice online tutor I instinctively reverted back to what many novice classroom practitioners do and focused on transmitting content, although this was something I would always try and avoid in a classroom setting.... recognise now that online learning is all about the activity of the student and what you get them to 'do'." (Watling, 2015)

\footnotetext{
2 https://www.futurelearn.com/

3 https://www.khanacademy.org/

4 https://www.coursera.org/

5 https://www.udacity.com/
} 


\section{Advice for coping with a pedagogy of uncertainty includes the use of signposts and acknowledging the complexity of VLE pedagogy and practice.}

E-teachers can help e-learners by providing appropriate signposting to manage expectations, indicate timescales, give key dates (such as assessment deadlines) and make clear the order and sequencing of activities. Sources of technical support, contact details for staff and guidance on participation in activities like online group work all need to be clearly signposted. It is useful to ask a critical friend who is unfamiliar with the learning environment to navigate around it and give feedback. The prevalence of social media creates a tendency to take for granted that e-learners can instinctively use VLE tools and have appropriate knowledge about what learning online involves. However, using a VLE for educational purposes often requires a more formal approach than the social habits encouraged by sites like Facebook and Instagram. Clear signposting to information on effective online learning, together with incentives to interact (like shared quizzes or treasure hunts) can help settle a new group and add a relaxed element which doesn't detract from formal learning but encourages the habit of logging on and checking for new content.

"Preparation is not just about being technically competent, it is about ensuring learners are able to deal with the social and emotional challenges of learning online too." (Watling, 2015)

\section{Summary}

This paper has shown how the TELEDA teacher education programme aimed to support academics to develop their digital pedagogy and practice and become more effective eteachers. The TELEDA course offered insight into the influences on the attitudes to their VLEs and on the practice of staff who teach and support learning. A number of findings emerged, including how deeply entrenched was the conception of a VLE as a place to put information: the prevalent primary focus was on transmitting content rather than approaching the VLE as a place to develop interactive learning opportunities. For many participants, the concept of e-teaching as the development and facilitation of online collaboration was a new approach. Though it could be argued that e-teaching is implicit within e-learning, the TELEDA experience suggests that, unless e-teaching is made explicit and unless teachers have the prerequisite technical and pedagogical knowledge to create effective online learning environments, there is a real risk that those mandating and promoting digital technology will continue to make unrealistic assumptions about baselines and starting points. TELEDA does give participants a realistic experience of e-learning: as a consequence of their participation, they reported increased empathy with the online experiences of their own students; their reflective journals and assessed eportfolios indicated how the experiential nature of the course design increased the likelihood of their going on to adopt digital ways of working in their own teaching practice.

\section{Conclusion}

In order to promote VLE engagement and develop teachers' potential for enhancing the student experience, there is a need to be realistic about where digital baselines and starting points are positioned. Achieving this requires conversations and partnerships between academics and education developers, as well as between departments responsible for technology training and those who lead on CPD and teacher education. TELEDA reinforced the value of experiential learning. Participants were immersed in real-world collaborations 
with colleagues and were supported in the adoption of new identities as e-teachers. Sharing thoughts and ideas about attitudes to VLEs and practices within them is now being incorporated into future digital development initiatives. This research shows how investing in the time and resources to support a shift from a technology training model to a teacher education one can significantly increase the rate of adoption of meaningful and relevant digital pedagogies and practice by staff who teach students and support their learning.

\section{Reference list}

Anderson, P. (2007) 'What is Web 2.0? Ideas, technologies and implications for education.' Jisc. Available at: http://www.jisc.ac.uk/media/documents/techwatch/tsw0701b (Accessed: 22 August 2015).

Bell, M. and Bell, W. (2005) 'It's installed... now get on with it! Looking beyond the software to the cultural change.' British Journal of Educational Technology, 36(4), 643-656.

Bennett, S. and Oliver, M. (2011) 'Talking back to theory: the missed opportunities in learning technology research.' Research in Learning Technology, 19(3), 179-189. Available at: http://dx.doi.org/10.1080/21567069.2011.624997 (Accessed: 29 July 2015).

Clegg, S., Hudson, A. and Steel, J. (2003) 'The Emperor's New Clothes: Globalisation and e-learning in Higher Education.' British Journal of Sociology of Education, 24(1),39-53. DOI: $10.1080 / 01425690301914$

Conole, G. (2004) 'E-Learning: The Hype and the Reality.' Journal of Interactive Media in Education, 11. Available at: http://www-jime.open.ac.uk/2004/12/ (Accessed: 29 July 2015).

Ecclesfield, N., Rebbeck, G. and Garnett, F. (2012) 'The case of the curious and the confident - the untold story of changing teacher attitudes to e-learning in the future education sector.' Compass: Journal of Learning and Teaching at the University of Greenwich, 5, 45-56. Available at:

https://journals.gre.ac.uk/index.php/compass/article/viewFile/71/107 (Accessed: 12 August 2015).

Feenberg, A. (2011) 'Agency and Citizenship in a Technological Society.' Presentation to the IT University of Copenhagen. Available at: http://www.sfu.ca/ andrewf/copen5-1.pdf (Accessed: 12 August 2015).

Freisen, N. (2008) 'Theory: Ideology Critique and the Myths of E-Learning.' Ubiquity, Vol 2008, Issue June, Article No. 2. ACM, New York. Available at:

http://ubiquity.acm.org/article.cfm?id=1386860 (Accessed 11 April 2016).

Garrison, R. (2011) E-Learning in the 21st Century: A Framework for Research and Practice. Second Edition. London: Routledge.

Goodyear, P., Salmon, G., Spector, M., Steeples, C. and Tickner, S. (2001) 'Competencies for Online Teaching: a special report.' Educational Technology, Research and Development, 49(1), 65-72. 
Gordon, N. (2014) Flexible Pedagogies. Technology Enhanced Learning. York: Higher Education Academy.

Gunn, C. and Steele, C. (2012) 'Linking theory to practice in learning technology research.' Research in Learning Technology 2012, 20(1), 14.

Healey, M., Flint, A. and Harrington, K. (2014) Engagement through partnership: students as partners in learning and teaching in higher education. York: Higher Education Academy.

Heirdsfield, A., Walker, S., Tambyah, M. and Beutel, D. (2011) 'Blackboard As An Online Learning Environment: What Do Teacher Education Students And Staff Think?' Australian Journal of Teacher Education, 36(7).

Jisc (2009) 'Higher Education in a Web 2.0 World.' Jisc. Available at: http://www.jisc.ac.uk/media/documents/publications/heweb20rptv1.pdf (Accessed: 28 July 2015).

Jisc (2013) 'Enable your staff to work with digital technologies.' Jisc. Available at: https://www.jisc.ac.uk/guides/enable-your-staff-to-work-with-digital-technologies (Accessed: 28 July 2015).

Jisc (2015) 'Building digital capability.' Jisc. Available at:

https://www.jisc.ac.uk/rd/projects/building-digital-capability (Accessed: 28 July 2015).

Killen, C. and Chatterton, P. (2015) 'Developing successful student-staff partnerships.' Jisc Change Agents Network. Available at: https://www.jisc.ac.uk/full-guide/developingsuccessful-student-staff-partnerships (Accessed: 11 April 2016).

Laurillard, D. (2001) Rethinking University Teaching: A Conversational Framework for the Effective Use of Learning Technologies. London: Routledge.

Lisewski, B. (2004) 'Implementing a learning technology strategy: top-down strategy meets bottom-up culture.' Research in Learning Technology, 12(2), 175-188.

NCIHE (1997) Higher education in the learning society. Report of the National Committee of Inquiry into Higher Education: 'The Dearing Report'. Norwich: HMSO.

Masterman, E. and Shuyska, J. A. (2010) 'Digitally mastered? Technology and transition in the experience of taught postgraduate students.' Learning, Media and Technology, 37(4), 2012.

Reeves, T., McKenney, S. and Herrington, J. (2011) 'Publishing and perishing: The critical importance of educational design research.' Australasian Journal of Educational Technology, 27(1), 55-65. Available at: http://ascilite.org.au/ajet/ajet27/reeves.html Accessed: 28 July 2015).

Säljö, R. (2010) 'Digital tools and challenges to institutional traditions of learning: technologies, social memory and the performative nature of learning.' Journal of Computer Assisted Learning, 26, 53-64.

Salmon, G. (2011) E-moderating, the key to online teaching and learning. 3rd edition. London: Routledge. 
Salmon, G. (2013) E-tivities, the key to active online learning. 2nd edition. London:

Routledge.

Selwyn, N. (2007) 'The use of computer technology in university teaching and learning: a critical perspective.' Journal of Computer Assisted Learning, 23, 83-94.

Selwyn, N. (2014) Distrusting Educational Technology. London: Routledge.

Sheward, L. and Hamilton, L. (2012) 'Designing and implementing an online PG Cert TLHE.' Educational Development, 13(1), 3-6. Available at:

http://www.seda.ac.uk/resources/files/publications 128 Ed\%20Devs\%2013.1\%20v4\%20FIN AL.pdf (Accessed: 28 July 2015).

Watling, S. (2009) 'Technology-Enhanced Learning: A New Digital Divide?' In: Bell, L., Stevenson, H. and Neary, M. (eds.) The Future of Higher Education: Policy, Pedagogy and the Student Experience. London: Continuum.

Watling, S. (2015) Doctoral research: unpublished research data. 